\title{
Reflexões sobre as principais linhas epistemológicas pertinentes às ciências da saúde
}

\author{
Reflections on the main epistemological currents regarding \\ health sciences
}

\begin{abstract}
É notório e indiscutível o progresso tecnológico da ciência, particularmente na área da saúde. O investimento financeiro gasto nesse setor cresceu exponencialmente em relação ao começo do século passado, e os próprios métodos propedêuticos e terapêuticos disponíveis aos profissionais da saúde possuem como base enunciados, teorias e leis científicas ${ }^{1}$. Entretanto, tal incremento tecnológico só foi possível graças a profundas reflexões filosóficas que existiram ao longo do tempo e que foram muitas vezes conflitantes ${ }^{2,3}$. Torna-se relevante conhecer as principais concepções filosóficas e sua influência na evolução das ciências da saúde, o que permite uma melhor compreensão sobre o dinamismo e a falibilidade destas ${ }^{1-3}$.

Pode-se definir a filosofia como o estudo que se caracteriza pela intenção humana de ampliar seu conhecimento sobre a realidade a fim de apreendê-la na sua totalidade, seja no "Ser" real materializado e/ou imaginário, seja na definição dos instrumentos capazes de comprovarem o pensamento, um fundamento, uma lei ou um princípio. A resenha, definida pelo Novo Aurélio Século XXI como a descrição pormenorizada sobre fatos, entre as correlações da filosofia com o método científico, nos possibilita enxergar que ao longo do tempo o pensamento filosófico cristalizava-se em diferentes correntes com definições e bases teóricas peculiares, as quais, no entanto, como senso comum, harmonizam e completam essas diferenças ${ }^{2,4,5}$.
\end{abstract}

Apesar da corrente de pensamento denominada positivismo lógico ou empirismo lógico ter sido criada inicialmente por matemáticos e físicos na Áustria, por volta de 1920, foi Comte seu principal personagem. O positivismo de Comte fundamentava-se nos princípios da lógica e da matemática como bases para o conhecimento ou a confirmação de hipóteses, já que estabeleciam regras independentes da experiência. Para Comte, até mesmo os enunciados gerais e as leis científicas poderiam ser obtidos a partir da observação ou da indução de um fenômeno, fosse este natural e/ou experimental ${ }^{2,6}$.

Entretanto, a corrente positivista enfrentou inúmeras críticas que se baseavam no fato de que toda observação científica está imersa em teorias, como, por exemplo, a mensuração da temperatura com termômetro de mercúrio, cujo princípio é o de que todos os metais se dilatam perante o aumento de suas temperaturas. E, diante da possibilidade de que as observações poderiam incorporar teorias falíveis, não seria possível considerálas como fontes seguras para se construir o conhecimento e tampouco como base sólida para o desenvolvimento científico.

Questionava-se ainda a validade do raciocínio indutivo, uma vez que a indução não é um argumento dedutivo e, portanto, não é logicamente válida. O grande exemplo disso é que antes da primeira constatação da existência de cisnes pretos, tinha-se como verdade que todos os cisnes eram brancos. A indução não poderia, portanto, ser justificada nem pela lógica, nem pela experiência ${ }^{2}$. A própria prática de evidências científicas salienta que se deve ter cautela com conclusões baseadas na experiência pessoal, independentemente da casuística profissional e do conhecimento científico do indivíduo ${ }^{1}$. 
A partir dessas reflexões, construiu-se o racionalismo crítico de Popper, fundamentado na tentativa de se alcançar a verdade acerca do método científico e do conhecimento em geral sem envolver apenas a indução, o que seria possível tendo como princípio a argumentação de que as observações só poderiam ser usadas para refutar (negar, reprovar) enunciados gerais, não sendo possível a evolução do conhecimento cujas teorias não estivessem abertas a críticas e a refutações. Popper definiu também que os enunciados potencialmente capazes de contradizer uma lei ou teoria seriam chamados de falseadores potenciais e que o conjunto desses falseadores serviria como parâmetro para o conteúdo empírico da teoria: quanto mais a teoria os "proibisse" - sendo eles identificados atualmente como critérios de exclusão -, mais ela nos diria acerca do mundo ${ }^{2,7}$. Portanto, a crítica científica é essencial para o próprio progresso científico $^{1,8,9}$.

Por fim, Popper afirmava que o grau de corroboração (aceitação) aumentava quando caminhávamos das teorias e pesquisas mais antigas para as mais recentes, da seguinte maneira: a busca do conhecimento iniciava-se com a formulação de hipóteses que procuravam resolver problemas e que deveriam resistir aos testes mais rígidos possíveis. Caso não resistissem, as hipóteses seriam refutadas e substituídas por outras que também seriam testadas e assim por diante ${ }^{2,7,10}$. Daí a importância da continuidade em pesquisa, da descrição detalhada do método, da análise estatística dos resultados e da publicação do estudo ${ }^{2,7,11}$. Porém, é importante entender que, mesmo depois de confirmadas, as hipóteses devem ser aceitas como soluções provisórias para o problema em questão e que, de igual modo, sua refutação será sempre conjetural, pois pode ter havido um erro na observação, no experimento ou ainda algum outro erro aleatório ${ }^{2-4,9}$.

Popper foi criticado pela corrente designada "a nova filosofia da ciência" representada por Kuhn, Lakatos e Feyerabend, que afirmavam: "os enunciados e os testes são impregnados de teorias; usualmente testamos sistemas teóricos complexos e não hipóteses isoladas"2,4,12,13. Para Thomas Kuhn, em Estrutura das revoluções científicas (1962), a simples observação de incompatibilidade ou refutação de uma teoria não seria justificativa para que o pesquisador a abandonasse; pelo contrário, ele deveria analisar de maneira madura as críticas e os resultados não comprovados a fim de salvar sua teoria, só justificando tal atitude diante dos seguintes fatos: significativa discrepância entre o previsto e o esperado, acúmulo de anomalias encontradas ou que impedissem sua aplicação prática e que resistissem por muito tempo, mesmo após a repetição ou mudança dos testes. Diante desses fenômenos, pesquisador se depararia com uma crise científica que, por sua vez, fomentaria a busca por um novo paradigma ${ }^{1,2,4,7,8,12}$. Ainda segundo Kuhn, nessas "revoluções científicas, ocorre uma mudança de paradigma, e embora o mundo não mude após uma mudança de paradigma, o cientista passa a enxergar e a trabalhar em um mundo diferente" ${ }^{p, 12}$.

Por outro lado, para Imre Lakatos (1922-1974) seria sempre possível evitar que uma teoria fosse refutada, desde que se fizessem modificações apenas nas hipóteses auxiliares, mantendo-se seu núcleo intacto, o que é, na verdade, uma das características de uma linha de pesquisa $^{1,2}$. Para Lakatos, a história da ciência demonstra que as teorias não são abandonadas, mesmo depois de refutadas. À semelhança de Thomas Kuhn, Lakatos afirmava que uma teoria científica pode ser a qualquer momento reabilitada, desde que alguns pesquisadores continuem trabalhando nela ${ }^{2,4,10,13}$. Esta é uma das razões para vivenciarmos ao longo do tempo condutas e pensamentos científicos que já foram usados em épocas passadas. Porém, torna-se imperativo analisar criticamente a justificativa de se tentar novamente algo que não conseguiu ser explicado e/ou aprovado anteriormente, analisando se há plausibilidade na proposta reacendida ${ }^{1,2,4,9}$.

Mas foi Feyerabend que ousou desafiar a lógica da harmonia científica. Com muita propriedade, ele criou a concepção anárquica da ciência ao afirmar que esta não tem um método próprio, uma regra rígida, e tampouco é uma atividade racional, mas sim um empreendimento anárquico no qual qualquer regra metodológica já proposta, inclusive as regras de lógica, foram em algum momento violadas pelos cientistas, constituindo-se numa etapa essencial para que a ciência progredisse ${ }^{2,4}$. Porém, ao mesmo tempo em que contrariava Kuhn, alegando não ver lugar para os critérios 
objetivos das avaliações, corroborava com seus antecessores ao afirmar que não se deveria abandonar uma teoria diante de refutações ${ }^{2,4,12,13}$. Apesar do aparente radicalismo de Feyerabend, a história da medicina corrobora parcialmente com o anarquismo proposto por $\mathrm{ele}^{10}$. Entretanto, atitudes contrárias aos princípios bioéticos atuais não são mais aceitas por parte de todos os envolvidos com o progresso científico ${ }^{8,9}$.

Finalmente, destacou-se ainda a sociologia da ciência, enfatizando a grande influência existente entre os fatores sociais e a atividade científica, segundo a qual é comum que as avaliações, as premiações e as publicações de trabalhos e pesquisas em revistas científicas relevantes sejam determinadas não apenas por seus conteúdos científicos, mas também por fatores sociais. A "vitória" desses trabalhos seria, então, fruto do resultado de uma disputa ou uma negociação entre cientistas, instituições ou até mesmo países ${ }^{2,4}$.

As afirmações da sociologia do conhecimento também foram bastante criticadas por diferentes setores, já que fica difícil aceitar que o sucesso da ciência tenha como base apenas as negociações e os interesses sociais e políticos. Além disso, sabe-se que uma das maneiras para se conseguir fama, sucesso profissional e verba é produzir estudos metodologicamente corretos ${ }^{1,2,14}$. Mas essas afirmações nos remetem, obrigatoriamente, a uma reflexão profunda sobre o tema.

Pode-se perceber, então, que as diferentes linhas filosóficas acerca do método científico permitiram amplo espaço para um debate maduro e altamente construtivo da própria ciência e que mudanças de paradigmas sempre ocorreram e continuarão a ocorrer. Não investir ou fugir do rigor científico implica abdicar-se da possibilidade de corrigir erros, abdicando-se assim do verdadeiro espírito da própria ciência.

\section{Ricardo Costa-Val}

Membro titular, SBACV. Mestre e Doutor, Universidade Federal de Minas Gerais (UFMG), Belo Horizonte, MG. Professor titular, Pós-Graduação: Mestrado Acadêmico em Ciências da Saúde, Universidade Vale do Rio Verde (UninCor), Betim, MG. Instituto de Previdência dos Servidores do Estado de Minas Gerais
(IPSEMG), Belo Horizonte, MG.

Correspondência: Rua Boa Esperança, 341/101, Bairro

Carmo, CEP 30310-730 - Belo Horizonte, MG.

Telefone: (31) 9972.6066

E-mail: ricardocostaval@hotmail.com

\section{Maria Cristina Marques}

Enfermeira gerente administrativa, Hospital Galba Ortopédico, Fundação Hospitalar do Estado de Minas Gerais (FHEMIG), Belo Horizonte, MG. Pósgraduanda, Auditoria em Sistemas de Saúde, Faculdade São Camilo, Belo Horizonte, MG. Enfermeira Coordenadora do Estudo Clínico (Fase 3) Internacional, Multicêntrico "F7 Trauma-1711" sob responsabilidade da Novo Nordisk ${ }^{\circledR}$, unidade Hospital de Pronto Socorro João XXIII, FHEMIG, Belo Horizonte, MG.

\section{Referências}

1. Drummond JP, Silva E, Coutinho M. Medicina baseada em evidências: novo paradigma assistencial e pedagógico. $2^{\mathrm{a}}$ ed. São Paulo: Atheneu; 2004.

2. Alves-Mazzotti AJ, Gewandsznajder F. A pesquisa científica. In: Alves-Mazzotti AJ, Gewandsznajder F. O método nas ciências naturais e sociais. São Paulo: Pioneira; 1999. p. 65-84.

3. Tanaka OY, Melo C. Reflexões sobre a avaliação em serviços de saúde e a adoção das abordagens qualitativa e quantitativa. In: Bosi MLM, Mercado FJ, organizadores. Pesquisa qualitativa de serviços de saúde.Rio de Janeiro: Vozes; 2004. p. 121-36.

4. Francelin MM. Ciência, senso comum e revoluções científicas: ressonâncias e paradoxos. Ci Inf. 2004;33:26-34.

5. Ferreira ABH. Novo Aurélio Século XXI ${ }^{\circledR}$ : o dicionário da língua portuguesa. Rio de Janeiro: Nova Fronteira/Lexikon Informática; 2005.

6. Comte A. Discurso preliminar sobre o espírito positivo. Edição eletrônica: Ridendo Catigad Mores. Disponível em: http://sociologia.incubadora.fapesp.br/portal/publicacoes-1/ apostilas/espirito_positivo_comte.pdf. Acessado: 28/07/ 2007.

7. Papineau D. Methodology: the elements of philosophy of science. In: Grayling AC, editor. Philosophy: a guide through the subject. London: Oxford University; 2000. p. 123-80.

8. Costa-Val R. A iminente mudança de paradigma na relação entre a indústria farmacêutica e a medicina. J Vasc Bras. 2007;6:104-6. 
9. El Dib RP. Como praticar a medicina baseada em evidências [editorial]. J Vasc Bras. 2007;6:1-4.

10. Margotta, R. The history of medicine. New York: Smithmark; 1996.

11. Yoshida WB. A nossa produção científica invisível. J Vasc Bras. 2005;4:113.

12. Assis JEP. Kuhn e as ciências sociais [dissertação]. São Paulo: FFLCH-USP; 1991.
13. Lakatos I. Criticism of the proof-analysis by counterexamples which are global but not local: the problem of rigour. In: Lakatos I. Proofs and refutations: the logic of mathematical discovery. London: Cambridge University; 1976. p. 42-50.

14. Drumond JGF. Os vinte anos da FAPEMIG. J Estado de Minas. Seção Opinião, março 2006, p. 11. 